ISSN: 2637-7764

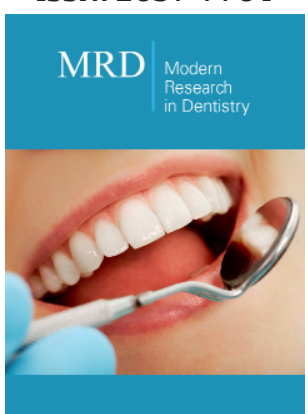

*Corresponding author: I-Ping Chen, D.D.S. Ph.D., Associate Professor, University of Connecticut Health

Division of Endodontology, Department of Oral Health and Diagnostic Sciences, 263

Farmington Avenue

Farmington, CT 06030-3705, USA

Submission: 望孟 July 28, 2020

Published: 監August 19, 2020

Volume 5 - Issue 3

How to cite this article: Do Hyeon Kim, Bruce Cha, Jin Jiang, I-Ping Chen. Prevalence and Morphology of MB2 Canals in Maxillary Molars by Cone Beam Computed Tomography (CBCT) and Rate of Treatment in Endodontic Practice with Pre-operative CBCT Images. Mod Res Dent. 5(3). MRD. 000614. 2020.

DOI: 10.31031/MRD.2020.05.000614

Copyright@ I-Ping Chen, This article is distributed under the terms of the Creative Commons Attribution 4.0 International License, which permits unrestricted use and redistribution provided that the original author and source are credited.

\section{Prevalence and Morphology of MB2 Canals in Maxillary Molars by Cone Beam Computed Tomography (CBCT) and Rate of Treatment in Endodontic Practice with Pre-operative CBCT Images}

\author{
Do Hyeon Kim , Bruce Cha², Jin Jiang ${ }^{2}$ and I-Ping Chen ${ }^{2 *}$ \\ ${ }^{1}$ Private Practice, Bridgeport, CT, USA \\ ${ }^{2}$ Department of Oral Health and Diagnostic Sciences, School of Dental Medicine, University of \\ Connecticut Health, Farmington, CT, USA
}

\begin{abstract}
Thorough understanding of root canal anatomy is a prerequisite for successful endodontic treatment. The failure of root canal treatment of maxillary molars is highly associated with missing the second mesiobuccal (MB2) canals.
\end{abstract}

Aim: we aim to assess the prevalence and morphology of MB2 canals of first $\left(1^{\text {st }}\right)$ and second $\left(2^{\text {nd }}\right)$ maxillary molars based on CBCT images. We further compared the treatment rate of MB2 canals to the rate identified from $\mathrm{CBCT}$ imaging analysis.

Methodology: Pre-operative CBCT images of 400 maxillary $1^{\text {st }}$ molars and 264 maxillary $2^{\text {nd }}$ molars in a cohort of 661 subjects were examined. Parameters studied were:
A. The root morphology.
B. The incidence of MB2 canals.
C. Vertucci classification of the MB root canals
D. The distance of MB2 orifice to pulpal floor and
E. The percentageof MB2 canals being treated

Result: $99 \%$ of maxillary $1^{\text {st }}$ and $89.77 \%$ of $2^{\text {nd }}$ molars had three separate roots with $2^{\text {nd }}$ molars showing higher morphological variability. MB2 canals were found in 77\% of maxillary 1st molars and $46.9 \%$ of $2^{\text {nd }}$ molars. In 3-rooted molars, the most common Vertucci classifications for MB canals in 1st molars were Type II (37.63\%) and in $2^{\text {nd }}$ molars Type I (47.26\%). When MB2 orifices were not at the pulpal floor level ( $\sim 50 \%$ of cases), the average distance below the pulp floor was $0.94 \mathrm{~mm}$ in maxillary $1^{\text {st }}$ molars and $0.92 \mathrm{~mm}$ in $2^{\text {nd }}$ molars. Clinically, the rates of MB2 canals being treated of $1^{\text {st }}$ and $2^{\text {nd }}$ molars were $67 \%$ and $37.8 \%$, respectively. With MB2 identified in CBCT images, $86.6 \%$ were obturated in maxillary $1^{\text {st }}$ and $80.64 \%$ in maxillary $2^{\text {nd }}$ molars.

Conclusion: Despite the resolution limit, CBCT remains a widely accepted non-destructive tool to study canal morphology and is readily available to many endodontists. When it is beneficial to patients and cost or radiation exposure is not a concern, pre-operative CBCT images should be thoroughly analyzed before treatment to ensure treatment quality and to limit iatrogenic complications.

Keywords: CBCT imaging; MB2 canals; Maxillary molars; Fused roots

\section{Introduction}

The morphology of maxillary molars has been extensively studied, particularly the prevalence of a second mesiobuccal (MB2) root canal. Despite of this effort, the high failure rate of root canal treated maxillary molars remains tightly associated with untreated MB2 canals. There is a significant increase in the incidence of MB2 canals in retreatment cases, suggesting that these canals are frequently missed in the initial treatment [1]. Moreover, maxillary $1^{\text {st }}$ 
molars with missed MB2 canals were 4.38 times more likely to be associated with a periapical lesion and, surprisingly, MB2 canals were unfilled in almost half of endodontic cases (46.5\%) [2]. To maximize the success rate of root canal treatment, it is important for endodontists to be aware of anatomic variations. Since the first report of MB2 canals in maxillary molars in 1925 [3], the prevalence of MB2 canals has been examined by many techniques, which may explain the variable results between studies. Some commonly used methods include clearing and staining of extracted teeth [4], various sectioning techniques [5,6], conventional/digital radiographs $[7,8]$, root canal treatment under microscope in vitro [9], and micro-computed tomographic imaging [10]. The incidence of MB2 canals in the literature ranges from 18-96\% [11].

Studies using clearing and staining techniques of extracted teeth revealed that more than $90 \%$ of maxillary molars have multiple canals in MB roots [12,13]. On the other hand, clinical studies reported lower incidence (18-73\%) of MB2 canals [14-16]. Such discrepancies could also be attributed to different selection criteria of sample population, such as ethnic background or age. Numerous studies have been conducted to establish a reliable and efficient clinical method to help locate MB2 canals [16-18]. In recent years, 3-dimensional cone-beam computed tomography (CBCT) has been used for identifying root canal configurations $[10,19,20]$. It can confirm the presence of MB2 canals as well as locate and orient a canal in relation to MB1, distobuccal, and palatal canals $[19,21]$. As a non-destructive tool, CBCT imaging offers not only high-resolution images in all spatial planes with minimal distortion but also reconstructs the volumetric images [22,23]. The aim of this study is to investigate the root and canal morphology of maxillary $1^{\text {st }}$ and $2^{\text {nd }}$ molars based on pre-operative CBCT images and associate the MB2 detection rate of CBCT with those being treated in clinic.

\section{Material and Methods}

\section{Subjects}

The protocol of this study was approved by the Pearl Institutional Review Board, Indiana, USA (19-KIM- 101). The study included pre-operative CBCT images of 400 maxillary $1^{\text {st }}$ and 264 maxillary $2^{\text {nd }}$ molars taken from 661 subjects between August 2014 and March 2019 for diagnostic purposes. The number of CBCT scans to be included in the study was determined by a power analysis using a sample size calculator (www.qualtrics.com) with a significant level of 0.05 and $99 \%$ power.

Inclusion criteria for CBCT images were as follows:

A. Pre-operative CBCT images of maxillary $1^{\text {st }}$ and $2^{\text {nd }}$ molars.

B. Teeth with complete root formation with fully mature apices.

The exclusion criteria were as follows:

A. Presence of root resorption or perforation.
B. Molars likely have MB2 canal based on indirect visualization (for example: MB1 canal was off-center) but MB2 canal was not visualized on either axial or coronal planes of CBCT image

C. Potential non-odontogenic pathology.

D. CBCT images of poor quality (e.g., presence of extensive beam hardening artifacts or resolution of CBCT image below optimal diagnostic quality).

E. Previous root canal treatment.

\section{Pre-operative evaluation of CBCT images}

CBCT images were taken with a Carestream CS 9000 3D (Carestream Dental, Atlanta, GA) using the following parameters: $70 \mathrm{kVp}, 10 \mathrm{~mA}, 10.8$ second exposure time, $76 \mathrm{~mm}$ voxel size, and $50 \mathrm{~mm} \times 37 \mathrm{~mm}$ scan field of view. Images were viewed with a 27 inch monitor (Samsung T27B350ND) at a screen resolution of $1920 \times 1080$ and luminance of $300 \mathrm{~cd} / \mathrm{m}^{2}$. Serial sagittal, coronal, and axial views of CBCT images were evaluated. In axial view, the axis of slicing was rotated to intersect with the long axis of the root. The presence of additional canals was most observable when scrolling the axial planes coronally to apically. In coronal and sagittal view planes, the axis of image slicing was rotated to be parallel to the long axis of the root, then the canal configuration was evaluated as the axis was scrolled in a mesio-distal and buccolingual plane, respectively. For samples with MB2 canals detected, the incidence of MB2 orifice appearing at the level of the pulpal floor was recorded. To determine the level of the pulpal floor, coronal and sagittal axes of image slicing were first adjusted to intersect at the center of the pulp space in axial view plane while maintaining the rotation of all 3 axes. Then, the axial axis was carefully adjusted to the level of pulpal floor in sagittal and coronal view plane. When the MB2 orifice did not appear at the pulpal floor level, the distance from the pulpal floor to MB2 orifice was measured. We studied the following parameters:
A. root morphologies.
B. the incidence of MB2 canals;
C. Vertucci classification of the MB root canals; and
D. the vertical distance of MB2 orifices to the pulpal floors.

Molars that have MB2 canals showing below mid root level, including molars of Vertucci classification type III (1-2-1) and V (12 ), were not included in the measurement of the vertical distance of MB2 orifices to the pulpal floors.

\section{Clinical management of MB2 canals}

All root canal treatments were performed under a dental operating microscope (OPMI PICO S100, Zeiss, Germany) by two endodontists in a private practice. After endodontic access was made and the MB1 canal was negotiated, the distance and orientation of MB2 orifice/canals were guided by CBCT images. 
The \#1 bur with a surgical shank on a high-speed handpiece and \#1/2 Mueller bur were used during the exploratory excavation. A Stropko irrigator tip (Spartan/Obtura, St. Louis, MO) was used to blow the dentin debris. Microscopic examination of the pulpal floor was used to locate the white dot created by the accumulation of the dentin debris. \#6, \#8, and \#10 files were used in discovery and initial negotiation of the MB2 canal. RC-Prep (Premier Dental, PA) and 17\% EDTA were routinely used during the exploration and discovery of MB2 orifices. $2.5 \% \mathrm{NaOCl}$ and $0.12 \%$ chlorhexidine were used as disinfecting irrigants. Once the canals were fully negotiated and shaped to the apical terminus, the canals were dried and obturated with gutta-percha and endodontic sealer.

\section{Post-operative evaluation with periapical radiographs}

Post-operative periapical radiographs were evaluated to determine the clinical treatment of MB2 canals. To be included and recorded as clinically treated, a MB2 canal had to be negotiated and obturated to its own apical terminus or merged with the MB1 canal.

\section{Result}

\section{Number and morphology of roots}

The morphology of maxillary $1^{\text {st }}$ and $2^{\text {nd }}$ molars is summarized in Tables $1 \& 2$, respectively. $99 \%$ of maxillary $1^{\text {st }}$ molars had 3 roots and $1 \%$ had 2 roots. Among maxillary $2^{\text {nd }}$ molars, $89.77 \%$ had 3 roots, $7.20 \%$ had 2 roots and $3.03 \%$ had a single root. Maxillary $2^{\text {nd }}$ molars showed higher variability in root morphology compared to maxillary $1^{\text {st }}$ molars. Roots were considered fused when there was an absence of alveolar bone in between the roots from the cementoenamel junction to the apex. The incidence of root fusion in maxillary $1^{\text {st }}$ and $2^{\text {nd }}$ molars was $3.25 \%$ and $13.25 \%$, respectively (Table 3). Of the fused roots, distobuccal root fused with palatal root was the most common morphology in maxillary $1^{\text {st }}$ molars (2.25\%), whereas it was the rarest in maxillary $2^{\text {nd }}$ molars $(0.38 \%)$. None of the maxillary $1^{\text {st }}$ molars had a MB root fused with a palatal root while $2.27 \%$ of $2^{\text {nd }}$ molars had such morphology. Three root fusions were found in $0.25 \%$ maxillary $1^{\text {st }}$ molars and $3.41 \%$ of $2^{\text {nd }}$ molars.

Table 1: Morphology (number of roots and canal classification) of maxillary $1^{\text {st }}$ molars.

\begin{tabular}{|c|c|c|c|c|c|c|c|c|}
\hline Molar Configuration & Root & Type I (1) & Type II (2-1) & $\begin{array}{l}\text { Type III } \\
(1-2-1)\end{array}$ & Type IV (2) & Type V (1-2) & $\begin{array}{l}\text { Type VI } \\
(2-1-2)\end{array}$ & $\begin{array}{l}\text { Type VII } \\
(1-2-1-2)\end{array}$ \\
\hline 1 root & & - & - & - & - & - & - & - \\
\hline \multirow{2}{*}{2 roots $(1 \%)$} & B & $2(50 \%)$ & $1(25 \%)$ & - & $1(25 \%)$ & - & - & - \\
\hline & $\mathrm{P}$ & $4(100 \%)$ & - & - & - & - & - & - \\
\hline \multirow{3}{*}{3 roots $(99 \%)$} & MB & $90(22.73 \%)$ & $149(37.63 \%)$ & $7(1.77 \%)$ & $134(33.84 \%)$ & $9(2.27 \%)$ & $7(1.76 \%)$ & - \\
\hline & DB & $396(100 \%)$ & - & - & - & - & - & - \\
\hline & $\mathrm{P}$ & $396(100 \%)$ & - & - & - & - & - & - \\
\hline
\end{tabular}

B: buccal; DB: distobuccal; MB: mesiobuccal; P: palatal

Values within parentheses are percentages of the total number of teeth in each group.

Table 2: Morphology (number of roots and canal classification) of maxillary $2^{\text {nd }}$ molars.

\begin{tabular}{|c|c|c|c|c|c|c|c|c|c|}
\hline Molar Configuration & Root & Type I (1) & $\begin{array}{c}\text { Type II } \\
(2-1)\end{array}$ & $\begin{array}{l}\text { Type III } \\
(1-2-1)\end{array}$ & Type IV (2) & Type V (1-2) & $\begin{array}{l}\text { Type VI } \\
(2-1-2)\end{array}$ & $\begin{array}{c}\text { Type VII } \\
(1-2-1-2)\end{array}$ & Other \\
\hline $1 \operatorname{root}(3.03 \%)$ & & $6(75 \%)$ & - & $1(12.5 \%)$ & - & - & - & - & $1(12.5 \%)^{*}$ \\
\hline \multirow{2}{*}{2 roots $(7.20 \%)$} & B & $14(73.68 \%)$ & $3(15.79 \%)$ & - & $2(10.53 \%)$ & - & - & - & - \\
\hline & $\mathrm{P}$ & $19(100 \%)$ & - & - & - & - & - & - & - \\
\hline \multirow{3}{*}{3 roots $(89.77 \%)$} & MB & $\begin{array}{c}112 \\
(47.26 \%)\end{array}$ & $\begin{array}{c}67 \\
(28.27 \%)\end{array}$ & $5(2.11 \%)$ & $\begin{array}{c}40 \\
(16.88 \%)\end{array}$ & $5(2.11 \%)$ & $6(2.53 \%)$ & $1(0.42 \%)$ & $1(0.42 \%)^{*}$ \\
\hline & DB & 237 (100\%) & - & - & - & - & - & - & - \\
\hline & $\mathrm{P}$ & $\begin{array}{c}236 \\
(99.58 \%)\end{array}$ & - & - & - & $1(0.42 \%)$ & - & - & - \\
\hline
\end{tabular}

B: buccal; DB: distobuccal; MB: mesiobuccal; P: palatal

Values within parentheses are percentages of the total number of teeth in each group.

${ }^{*} \mathrm{C}$-shaped canal system. 
Table 3: Percentage of fused roots in maxillary $1^{\text {st }}$ and $2^{\text {nd }}$ molars.

\begin{tabular}{|c|c|c|}
\hline Root Morphology & Maxillary 1 $\mathbf{1}^{\text {st }}$ Molars (n=400) & Maxillary 2 ${ }^{\text {nd }}$ Molars (n=264) \\
\hline All roots separate & $387(96.75 \%)$ & $229(86.75 \%)$ \\
\hline MB fused with DB & $2(0.5 \%)$ & $6(2.27 \%)$ \\
\hline MB fused with P & $0(0 \%)$ & $1(0.38 \%)$ \\
\hline DB fused with P & $9(2.25 \%)$ & $5(1.89 \%)$ \\
\hline B and P fused to a cone shaped root (2 rooted molars) & $1(0.25 \%)$ & $9(3.41 \%)$ \\
\hline MB, P, DB fused to a cone shaped root & $1(0.25 \%)$ & \\
\hline
\end{tabular}

Values within parentheses are percentages of the total number of teeth in each group.

\section{Number and configuration of root canals}

MB2 was present in $77 \%$ maxillary $1^{\text {st }}$ molars and in $46.9 \%$ maxillary $2^{\text {nd }}$ molars. All MB2 canals were once visualized as radiolucent dots on axial planes and/or lines on coronal planes. Root canal configuration of MB roots in maxillary $1^{\text {st }}$ and $2^{\text {nd }}$ molars was analyzed based on the Vertucci's classification shown in Table $1 \& 2$. In 3-rooted maxillary $1^{\text {st }}$ molars, Type II morphology was the most common, followed by Type IV and Type I. In the 2-rooted maxillary $1^{\text {st }}$ molars, $50 \%$ had a single canal in B root, $25 \%$ had Vertucci Type II, and 25\% had Type IV. In the 3-rooted maxillary 2nd molars, MB roots showed all variations from Type I to Type VII as well as C-shaped canals that did not fall under the Vertucci classification system. Type I root canal configuration was most common in $\mathrm{MB}$ roots of 3-rooted maxillary $2^{\text {nd }}$ molars, followed by Type II and Type IV. In 2-rooted maxillary $2^{\text {nd }}$ molars, $73.68 \%$ had single canals in buccal roots while $15.79 \%$ had Type II and $10.53 \%$ had Type IV. In 1-rooted maxillary $2^{\text {nd }}$ molars, $75 \%$ showed one canal, $12.5 \%$ had Type III, and $12.5 \%$ had C-shaped canal systems. Examples of variable root canal morphologies are shown in Figure 1.

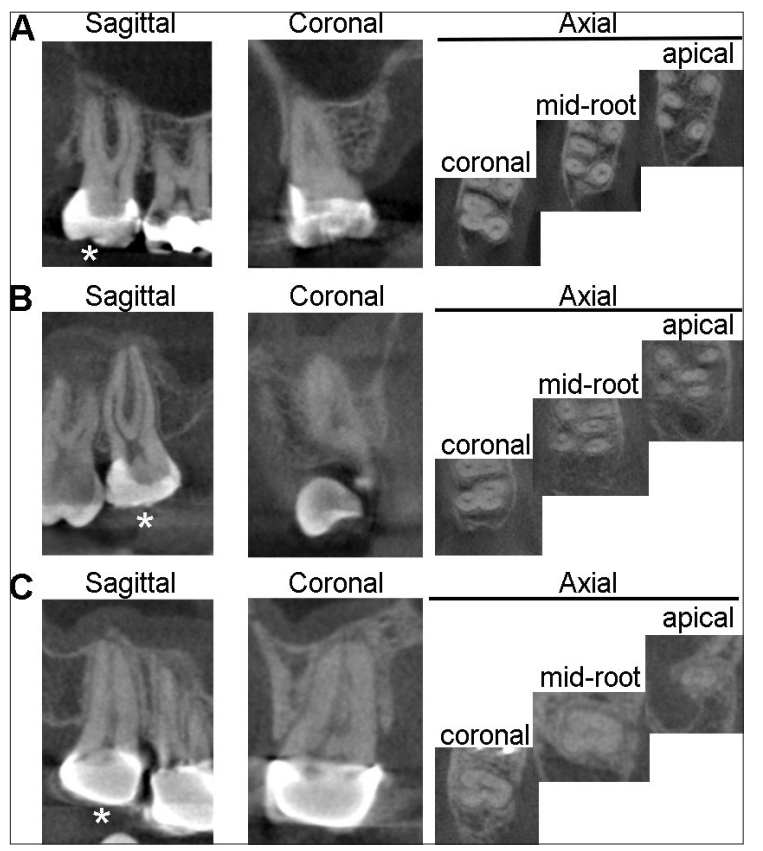

Figure 1: Representative CBCT images showing sagittal, coronal, and axial planes of

A) One maxillary $1^{\text {st }}$ molar with type II (2-1) MB canals.

B) One $2^{\text {nd }}$ molar with type IV (1-2) MB canals.

Notice thedisappearance of MB canal on the sagittal plane indicating the bifurcation of canals.

C) One $2^{\text {nd }}$ molar with C-shaped canal.

*indicated the tooth of interest. 


\section{Incidence of MB2 orifice on the pulpal floor}

Out of 448 samples with MB2 canals, 212 maxillary $1^{\text {st }}$ molars and 124 maxillary $2^{\text {nd }}$ molars were included in the analysis. Excluded images were due to the MB2 canal bifurcating below mid-root level or presence of artifacts on the pulpal floor due to extensive restoration or caries. The incidence of MB2 orifices appearing at the pulpal floor was $53 \%$ in maxillary $1^{\text {st }}$ molars and $48 \%$ in $2^{\text {nd }}$ molars. In instances where the MB2 orifice did not appear at the pulpal floor level, the average distance from the pulpal floor to the MB2 orifice was $0.94 \pm 0.58 \mathrm{~mm}$ for maxillary $1^{\text {st }}$ molars and $0.92 \pm 0.53 \mathrm{~mm}$ for $2^{\text {nd }}$ molars measured from pre-operative CBCT images.

\section{The incidence of clinically treated MB2 canals}

We next examined the number of all MB2 canals being clinically treated to the frequency of molars that have MB2 canals identified on pre-operative CBCT images. Approximately $30 \%$ of teeth had full-coverage crowns present at the time of treatment. Our data showed that $66.7 \%$ of $1^{\text {st }}$ and $37.82 \%$ of $2^{\text {nd }}$ molars had MB2 canals negotiated and obturated. There was no significant difference on the prevalence of MB2 canals being treated with ( $1^{\text {st }}$ molars: $87.4 \%$, 2nd molars: $82.1 \%$ ) or without $\left(1^{\text {st }}\right.$ molars: $86.2 \%, 2^{\text {nd }}$ molars: $80.2 \%$ ) the presence of crown restoration. The rate of MB2 canals being clinically treated was approximately $10 \%$ lower than those identified on CBCT images. Of the MB2 canals that were identified from pre-operative CBCTs, $86.6 \%$ of maxillary $1^{\text {st }}$ molars and $80.64 \%$ of maxillary $2^{\text {nd }}$ molars were clinically treated.

\section{Discussion}

In this study, we analyzed root and canal morphology of 664 maxillary $1^{\text {st }}$ and $2^{\text {nd }}$ molars using CBCT images and associated the MB2 detection rate of CBCT with clinical outcome. Our data suggest that a higher percentage of MB2 canals in maxillary $1^{\text {st }}$ molars and more anatomical variations in maxillary $2^{\text {nd }}$ molars. We only identified C-shaped canals in maxillary $2^{\text {nd }}$ molars and found a higher incidence in $2^{\text {nd }}$ molars with only one root. We also found a palatal root with 2 canals bifurcating at mid-root level of one maxillary $2^{\text {nd }}$ molar. Fused roots should be considered as part of treatment planning for apicoectomy involving a specific root. While apicoectomy is mostly done in MB roots of maxillary $1^{\text {st }}$ molars, the chance of an MB root fused with any other root is lower than $1 \%$. The top three most common canal types of MB roots of $1^{\text {st }}$ molars are Vertucci type II (2-1), IV (2) and I (1). For $2^{\text {nd }}$ molars are type I, II, and IV. This is consistent with a previous study using coronal plane root sectioning that Vertucci type II and IV are the most common configuration of $1^{\text {st }}$ maxillary molars with MB2 canals [24].

Many factors can affect the identification of MB2 canals, such as age, ethnicity, and the presence of crown etc. A CBCT study showed that the detection rate of MB2 canals is significantly higher in younger patients (20-30-year-old) than older patients (60-70yearold) [25]. A recent CBCT study found the overall prevalence of MB2 canals in 21 geographic regions to be $73.8 \%$ [26]. In a Chilean population, the prevalence of MB2 canals was found to be
$73.44 \%$ in maxillary $1^{\text {st }}$ molars and $42.88 \%$ in $2^{\text {nd }}$ molars [27]. In North Americans, the prevalence of MB2 canals in $1^{\text {st }}$ molars was $68.2 \%$ [28]. Another study showed that the rate of MB2 canals was $85.4 \%$ for maxillary $1^{\text {st }}$ molars in Chinese [21] while in Brazilians the prevalence of MB2 canals was remarkably lower with $42.63 \%$ reported for maxillary $1^{\text {st }}$ molars and $34.32 \%$ for $2^{\text {nd }}$ molars [29]. Studebacker et al. [18] showed that during initial treatment, MB2 canals were detected more often in maxillary $1^{\text {st }}$ molars without a crown (66\%) than molars with a crown (50\%) but there was no statistically significance in maxillary $2^{\text {nd }}$ molars and for retreatment cases [18]. Our study participants are North Americans with a wide distribution of age, mostly older than 40 years. We found no significant difference in the treatment rate of MB2 canals in maxillary molars with or without full-coverage crowns.

Extensive tertiary dentin deposition or calcification above MB2 orifices due to aging or pathology often makes the detection of MB2 canals challenging. Vertical troughing is as important as the horizontal position for negotiating MB2 canals. Park et al. \& Yoshioka et al. $[30,31]$ reported that most MB2 canals could be found with average troughing depths of $2.7 \mathrm{~mm}$ and $2 \mathrm{~mm}$, respectively [30,31]. Here we found that approximately half of the MB2 canals (53\% for $1^{\text {st }}$ molars and $48 \%$ for $2^{\text {nd }}$ molars) appear at the pulpal floor. The rest of MB2 canals that are detectable ranged from $0.36 \mathrm{~mm}$ to $1.52 \mathrm{~mm}$, with an average about $1 \mathrm{~mm}$, below the pulpal floor. Zhang et al. [21] reported $94.9 \%$ of MB2 orifices appearing at the pulpal floor level in the maxillary $1^{\text {st }}$ molar with an average vertical distance of $0.76 \mathrm{~mm} \pm 0.35 \mathrm{~mm}$ below the pulpal floor when MB2 orifice does not appear on the pulpal floor [21]. Differences between studies may be in part caused by different sample sizes and analytical techniques. The field of view of CBCT scans were $18 \mathrm{~cm} \times 16 \mathrm{~cm}$ in the previous study [21] and $50 \mathrm{~mm} \times 37 \mathrm{~mm}$ in our study. In addition, Zhang et al. [21] used only axial axis [21] whereas we adjusted all three axes, sagittal, axial, and coronal planes, of each tooth being studied using oblique slicing mode. In our study, MB2 canals of 22 molars could only be visualized on the coronal plane but not on the axial plane. The other reason that our results showed less vertical distance than other studies could be due to our exclusion criteria of extensive calcification in order to discern the canal configuration of Vertucci classification on CBCT images. This is a limitation of our study because we excluded molars with MB2 canals that were not directly visualized.

Two other clinical studies investigated the rate of MB2 canals in private endodontics practices with provider experience and a study period (5-8 years) comparable to our study [1,15]. For $1^{\text {st }}$ molars, the prevalence of MB2 canals was 58\% [1], 60\% [15] and $66.7 \%$ (our study) [1,15]. For $2^{\text {nd }}$ molars, the reported incidence of MB2 canals was 34\% [1], 42\% [15] and 37.8\% (our study) [1,15]. Although the results are relatively comparable, several differences may attribute to slightly different reporting rates. First, the preCBCT images were only available in our study; second, our study was the only one that used the dental microscope for all procedures; and third, criteria of MB2 canals are different. Wolcott et al. [1] recorded MB2 canal as present only when the canal was obturated 
to its own apex or when it merged with the MB1 canal within $5 \mathrm{~mm}$ of the apex [1]. In Stropko's [15] study, 16\% of MB2 canals that were clinically detected could not be fully instrumented and were classified as unfilled canals [15].

The effectiveness of pre-operative CBCT to locate MB2 canals in clinical settings remains controversial. Some studies conclude that CBCT has a limited role in the detection of MB2 canals $[24,32,33]$. Parker et al., showed that CBCT images identified 5 out of 15 molars (33\%) with MB2 canals while 8 teeth (53\%) with existing MB2 canals were found during root canal treatment [33]. Hiebert et al. [24] showed that CBCT analysis reveals the presence of MB2 canals $69 \%$ of the time in 100 extracted molars while the detection rate of MB2 is $92 \%$ by coronal plane root grinding [24]. In contrast, Studebaker et al., showed that pre-operative CBCT scans significantly increase the incidence of treated MB2 canals of maxillary molars from $54.5 \%$ to $76 \%$ [18]. In our study we review 664 CBCT images and show that more MB2 canals are being identified in CBCT images than during treatment. This could be mainly due to teeth that have one common MB orifice that bifurcate into MB1 and MB2 canals in mid root levels, such as Vertucci class III (1-2-1), V (1-2), VII (1-2-1-2) canals, and the subsequent clinical decision to prematurely stop horizontal and vertical troughing in order to preserve coronal tooth structure.

The pre-operative CBCT imaging serves as an "endodontic 3-dimensional map" and can be beneficial for endodontic treatment of complex root canal configurations. CBCT can potentially better guide conservative endodontic access preparation, detect root canal morphology, and prevent procedural errors such as perforation, fracture, or missed canals. The major concerns for the routine use of CBCT are radiation exposure and cost to the patient [34]. The radiation dose of a small field of view of maxillary molars is substantially lower than for mandibular molars and is roughly equivalent to that of two digital periapical radiographs [35]. When benefits weigh more than risks, we recommend to perform CBCTguided endodontic treatment in identifying MB2 canals of maxillary molars.

\section{Conclusion}

In summary, for maxillary $1^{\text {st }}$ molars, 3 separate roots and 4 canals are the most common morphology whereas most of the maxillary $2^{\text {nd }}$ molars have 3 separate roots and 3 canals. Maxillary $2^{\text {nd }}$ molars have more anatomic variations than $1^{\text {st }}$ molars. The prevalence of MB2 canals in $1^{\text {st }}$ and $2^{\text {nd }}$ molars were $77 \%$ and $46.9 \%$ based on CBCT images. These rates were slightly decreased to $66.7 \%$ of $1^{\text {st }}$ and $37.82 \%$ of $2^{\text {nd }}$ molars by clinical outcome. For radiation exposure, endodontists should follow the principle of "as low as reasonably achievable" but use CBCT when there is a benefit for patient treatment, such as for identifying MB2 canals of maxillary molars.

\section{Acknowledgment}

The authors deny any conflicts of interest related to this study.

\section{References}

1. Wolcott J, Ishley D, Kennedy W, Johnson S, Minnich S, et al. (2005) A 5yr clinical investigation of second mesiobuccal canals in endodontically treated and retreated maxillary molars. J Endod 31(4): 262-264.

2. Karabucak B, Bunes A, Chehoud C, Kohli MR, Setzer F (2016) Prevalence of apical periodontitis in endodontically treated premolars and molars with untreated canal: a cone-beam computed tomography study. J Endod 42(4): 538-541.

3. Hess W, Zürcher E, Dolamore WH (1925) The anatomy of the root-canals of the teeth of the permanent dentition, J. Bale, sons \& Danielsson, ltd., London, England.

4. Vertucci FJ (1984) Root canal anatomy of the human permanent teeth. Oral Surg Oral Med Oral Pathol 58(5): 589-599.

5. Weine FS, Healey HJ, Gerstein H, Evanson L (1969) Canal configuration in the mesiobuccal root of the maxillary first molar and its endodontic significance. Oral Surg Oral Med Oral Pathol 28(3): 419-425.

6. Seidberg BH, Altman M, Guttuso J, Suson M (1973) Frequency of two mesiobuccal root canals in maxillary permanent first molars. J Am Dent Assoc 87(4): 852-856.

7. Weine FS, Hayami S, Hata G, Toda T (1999) Canal configuration of the mesiobuccal root of the maxillary first molar of a Japanese subpopulation. Int Endod J 32(2): 79-87.

8. Pattanshetti N, Gaidhane M, Al Kandari AM (2008) Root and canal morphology of the mesiobuccal and distal roots of permanent first molars in a Kuwait population--a clinical study. Int Endod J 41(9): 755762.

9. Gorduysus MO, Gorduysus M, Friedman S (2001) Operating microscope improves negotiation of second mesiobuccal canals in maxillary molars. J Endod 27(11): 683-686.

10. Domark JD, Hatton JF, Benison RP, Hildebolt CF (2013) An ex vivo comparison of digital radiography and cone-beam and micro computed tomography in the detection of the number of canals in the mesiobuccal roots of maxillary molars. J Endod 39(7): 901-905.

11. Cleghorn BM, Christie WH, Dong CC (2006) Root and root canal morphology of the human permanent maxillary first molar: a literature review. J Endod 32(9): 813-821.

12. Gilles J, Reader A (1990) An SEM investigation of the mesiolingual canal in human maxillary first and second molars. Oral Surg Oral Med Oral Pathol 70(5): 638-643.

13. Sert S, Bayirli GS (2004) Evaluation of the root canal configurations of the mandibular and maxillary permanent teeth by gender in the Turkish population. J Endod 30(6): 391-398.

14. Hartwell G, Bellizzi R (1982) Clinical investigation of in vivo endodontically treated mandibular and maxillary molars. J Endod 8(12): 555-557.

15. Stropko JJ (1999) Canal morphology of maxillary molars: clinical observations of canal configurations. J Endod 25(6): 446-450.

16. Buhrley LJ, Barrows MJ, BeGole EA, Wenckus CS (2002) Effect of magnification on locating the MB2 canal in maxillary molars. J Endod 28(4): 324-327.

17. Weller RN, Hartwell GR (1989) The impact of improved access and searching techniques on detection of the mesiolingual canal in maxillary molars. J Endod 15(2): 82-83.

18. Studebaker B, Hollender L, Mancl L, Johnson JD, Paranjpe A (2018) The incidence of second mesiobuccal canals located in maxillary molars with the aid of cone-beam computed tomography. J Endod 44(4): 565-570.

19. Blattner TC, George N, Lee CC, Kumar V, Yelton CD (2010) Efficacy of cone-beam computed tomography as a modality to accurately identify 
the presence of second mesiobuccal canals in maxillary first and second molars: a pilot study. J Endod 36(5): 867-870.

20. Michetti J, Maret D, Mallet JP, Diemer F (2010) Validation of cone beam computed tomography as a tool to explore root canal anatomy. J Endod 36(7): 1187-1190.

21. Zhang Y, Xu H, Wang D, Gu Y, Wang J, et al. (2017) Assessment of the second mesiobuccal root canal in maxillary first molars: A cone-beam computed tomographic study. J Endod 43(12): 1990-1996.

22. Cotton TP, Geisler TM, Holden DT, Schwartz SA, Schindler WG (2007) Endodontic applications of cone-beam volumetric tomography. J Endod 33(9): 1121-1132.

23. Tian XM, Yang XW, Qian L, Wei B, Gong Y (2016) Analysis of the root and canal morphologies in maxillary first and second molars in a Chinese population using cone-beam computed tomography. J Endod 42(5): 696701.

24. Hiebert BM, Abramovitch K, Rice D, Torabinejad M (2017) Prevalence of second mesiobuccal canals in maxillary first molars detected using cone-beam computed tomography, direct occlusal access, and coronal plane grinding. J Endod 43(10): 1711-1715.

25. Reis AG, Grazziotin-Soares R, Barletta FB, Fontanella VR, Mahl CR (2013) Second canal in mesiobuccal root of maxillary molars is correlated with root third and patient age: a cone-beam computed tomographic study. J Endod 39(5): 588-592.

26. Martins JNR, Alkhawas MAM, Altaki Z, Bellardini G, Berti L, et al. (2018) Worldwide analyses of maxillary first molar second mesiobuccal prevalence: a multicenter cone-beam computed tomographic study. J Endod 44(11): 1641-1649.e1.

27. Abarca J, GómezB, Zaror C, Monardes H, Bustos L, et al. (2015) Assessment of mesial root morphology and frequency of MB2 canals in maxillary molars using cone-beam computed tomography. Int J Morphol 33(4): 1333-1337.

28. Guo J, Vahidnia A, Sedghizadeh P, Enciso R (2014) Evaluation of root and canal morphology of maxillary permanent first molars in a North American population by cone-beam computed tomography. J Endod 40(5): 635-639.

29. Silva EJ, Nejaim Y, Silva AI, Haiter Neto F, Zaia AA, et al. (2014) Evaluation of root canal configuration of maxillary molars in a Brazilian population using cone-beam computed tomographic imaging: an in vivo study. J Endod 40(2): 173-176.

30. Park E, Chehroudi B, Coil JM (2014) Identification of possible factors impacting dental students' ability to locate MB2 canals in maxillary molars. J Dent Educ 78(5): 789-795.

31. Yoshioka T, Kikuchi I, Fukumoto Y, Kobayashi C, Suda H (2005) Detection of the second mesiobuccal canal in mesiobuccal roots of maxillary molar teeth ex vivo. Int Endod J 38(2): 124-128.

32. Plotino G, Tocci L, Grande NM, Testarelli L, Messineo D, et al. (2013) Symmetry of root and root canal morphology of maxillary and mandibular molars in a white population: a cone-beam computed tomography study in vivo. J Endod 39(12): 1545-1548.

33. Parker J, Mol A, Rivera EM, Tawil P (2017) CBCT uses in clinical endodontics: the effect of CBCT on the ability to locate MB2 canals in maxillary molars. Int Endod J 50(12): 1109-1115.

34. Setzer FC, Hinckley N, Kohli MR, Karabucak B (2017) A survey of conebeam computed tomographic use among endodontic practitioners in the United States. J Endod 43(5): 699-704.

35. F B (2011) Cone beam-computed tomography in endodontics. Colleagues for Excellence. 